\title{
Piloting a Faculty Institute for Online Teaching
}

\section{Caitlin Ashley Keller, Worcester Polytechnic Institute}

Caitlin Keller is the Instructional Designer for Worcester Polytechnic Institute. Her primary role involves partnering with teaching faculty to create and develop courses in the online, blended, and face-to-face environments. Caitlin serves as the designer, facilitator, and instructional design consultant for the Faculty Institute for Online Teaching program. Caitlin holds a Master of Science degree in Learning Technologies and Instructional Design from Drexel University and a Bachelor of Science degree in Chemistry from Lebanon Valley College.

\section{Mrs. Stacy L. Chiaramonte, Worcester Polytechnic Institute}

Stacy Chiaramonte is the Director of Operations and Online Learning for WPI's Corporate and Professional Education (CPE) division. Stacy is directly responsible for online strategy, program development, logistics and operations for WPI Online, as well as the logistics and operations for numerous corporate graduate programs. During Stacy's tenure, WPI Online has doubled the number of programs and enrolled students while increasing student support and quality. Stacy holds a Bachelor's in Business Administration from the University of Massachusetts, Amherst and a MBA from Babson College.

\section{Dr. Beth Wilson, Worcester Polytechnic Institute}

Dr. Beth Wilson earned her PhD in Electrical Engineering from the University of Rhode Island and is currently an Adjunct Professor at Worcester Polytechnic Institute. She is co-chair for the International Council on Systems Engineering (INCOSE) Systems Security Working Group and is an INCOSE Expert Systems Engineering Professional (ESEP). Dr. Wilson is retired from Raytheon where she worked for 33 years as a design engineer, program manager, research scientist, functional manager, and test director on sonar, satellite, and radar programs.

\section{Kate Beverage, Worcester Polytechnic Institute}

Kate's primary responsibility is to lead the Academic Technology Center's outreach efforts to the Worcester Polytechnic Institute community with regards to the use of instructional technologies in teaching and learning. Kate also collaborates with academic departments concerning the policies, planning, and management of e-learning and blended initiatives on campus.

\section{Rachel LeBlanc, Worcester PoIytechnic Institute}

Rachel LeBlanc is the Executive Director of Corporate and Professional Education at Worcester Polytechnic Institute. She manages the portfolio of non-traditional academic programs for the University including online programs, corporate education, and professional education. Rachel has over fourteen years of experience working with faculty and industry experts to create education solutions to meet business needs. She manages a variety of functional areas including business development, marketing, product development, and operations. Throughout her career, Rachel and her team have provided education solutions for several industries including defense, life science, high-tech, energy, healthcare, manufacturing, and construction. Rachel currently serves on the Board of Directors for the International Council on Systems Engineering (INCOSE) and AUVSI New England. Rachel has a B.S. and M.S. in the life sciences, as well as an M.B.A.

\section{Dr. Terri A. Camesano, Worcester Polytechnic Institute}

Professor Camesano is Dean of Graduate Studies and Professor of Chemical Engineering at Worcester Polytechnic Institute.

\section{Jody Reis, Worcester Polytechnic Institute}


Jody Reis is a Senior Program Manager, Online Learning at Worcester Polytechnic Institute in the Corporate and Professional Education Department. Her division specializes in the learning needs of working professionals and is committed to helping working professionals achieve their educational goals. Jody has been with WPI since 2007. In her current role she is responsible for the overall student and faculty experience in WPI's online education programs. Key aspects include managing the day-to-day operations, as well as working with the faculty and students, to enhance the quality of WPI's educational online offerings for part-time and non-traditional students. This includes developing processes, initiatives, evaluation methods and operational procedures that affect successful online delivery. Additionally, she plays a key role in development of the faculty and student support services required for a successful online program. Jody graduated from Ithaca College in 2004 with a degree in Business Administration. In 2011, she earned her Master of Science in Marketing and Innovation from Worcester Polytechnic Institute. 


\title{
Piloting a Faculty Institute for Online Teaching
}

\author{
Worcester Polytechnic Institute
}

\begin{abstract}
As an institution, Worcester Polytechnic Institute (WPI) has been delivering distance education for decades and internet-based courses for 15 years. This long history has been both beneficial and challenging. On the one hand, we have not been met with resistance to the idea of online education that many institutions have faced, because our faculty already have a history of participation. The faculty have been teaching online courses for many years and have developed their own individual methodology for how to best deliver these courses. On the other hand, as most of the knowledge came about empirically through faculty developing online teaching methods on an individual basis, we did not have a formalized professional development opportunities for faculty who wanted to become engaged in online teaching or improve their current offerings. Much research has been done in the last several years to highlight the best practices in online learning. To better benefit from this research, we launched a pilot effort to create a Faculty Institute for Online Teaching. The goal of this effort is to inform the understanding of what it means to deliver a high-quality online experience to students from around the globe. These best practices include organization of courses and programs within the learning management system, designing lectures for online delivery, feedback timelines, student to faculty engagement, and peer to peer engagement. This Institute had 30 participants enrolled in the pilot, and $73 \%$ completed, resulting in 22 new or substantially modified online courses being delivered.
\end{abstract}

\section{Introduction/Background}

WPI has been delivering distance education for over 30 years. For the university, this began with video-tape based distance learning in 1980 when the then Management Department (now School of Business) developed a partnership with a few key companies to deliver the MBA program at their locations. As was often the case at that time, the enrollments for the on-site program were low and the program shifted to video-taped lectures rather than face-to-face instruction. The Fire Protection Engineering program soon learned that there was great demand for their program outside of the state and began distance education via video-taped lectures as well.

In 1999, the current WPI President, included distance learning at the graduate level in the university's mission statement and strategic plan. This prompted the first investment into resources to support distance learning and the university began to hire support staff and seek tools to drive distance learning.

The university signed on with Blackboard for course management in 1999, and was one of the first 6 universities to do so. A distance learning team consisting of academic technologists and 
marketing was assembled in 2000. Another engineering program launched a distance learning program via video-tapes at this time as well.

At the same time the university was starting to be constrained by the capacity of the TV studio to capture lectures on video, the department head for the management program also began to feel that video-taped lectures were not the most effective and made the move to $100 \%$ online delivery in 2001. This meant that lectures were to be recorded separately for online delivery. By 2005, the university fully transitioned away from video-tape to online courses as high speed Internet access and the resources for students became more commonplace.

WPI has historically been at the forefront of distance learning. We were one of the first nationally-ranked institutions to embrace online education and were an early adopter of technology. The university has continued to add resources to support online education and the faculty have consistently put a great deal of effort into online education. That effort and early adoption however, has also led to a challenge in terms of faculty development and ensuring online content is kept both fresh and current.

The university's path to building online learning was quite "home grown" in nature. The faculty identified what they believed to be the best methods to deliver online education. Faculty put a great deal of effort into course development and were using the best methods and technology available at the time. They learned by doing and became proficient on their own, without any guidance or any type of quality metrics to benchmark.

\section{Growth in Online Education and the Need for Quality}

Online education at WPI has grown steadily over the past several years. In the fall of 2015, there were 633 part-time students enrolled in online courses compared to just 129 in 2007. Additionally, full-time, campus-based students are opting to take online sections of courses at higher rates, increasing the enrollment in online courses at WPI significantly.

According to "Grade Change: Tracking Online Education in the United States", the number students taking at least one online course grew by 412,000 students from fall 2011 to fall 2012. This brought the total to 1.7 million students taking at least one online course and online enrollment as a percentage of total enrollment to $33.5 \%$, the highest since they began this study in 2002 (Allen and Seamen, 2014).

While enrollment in online programs and courses is growing, the need for quality and consistency in online education is also increasing. Early on, students opted for online courses simply as a matter of convenience. However, students today are smart consumers, with many choices about which university to attend for their online education, making the online education market extremely competitive. The quality of the online program and interaction with instructors are key factors in a student's decision about which school to select. While many of WPI's online programs are more niche, there is at least one other school offering even our unique programs, in many cases at a lower tuition cost. Therefore, the quality of our online course delivery, coupled with the support we provide to students, must be a key differentiator for us. 
According to a 2015 study titled "Online College Students 2015: Comprehensive Data on Demands and Preferences", a joint project of The Learning House, Inc. and Aslanian Market Research led by Dr. David L. Clinefelter and Carol Aslanian, key concerns with online learning included:

- Perceptions of quality of online study $-27 \%$ of respondents

- Inconsistent/poor contact and communication with instructors $-21 \%$ of respondents

- Lack of direct contact with other students $-17 \%$ of respondents

- Inconsistent/poor quality of instruction $-17 \%$ of respondents

The only two other concerns with a higher number of respondents were motivation/attention/focus challenges at 27\% and cost at 16\% (Clinefelter and Aslanian, 2015).

When you review the data about online student preferences, it very quickly becomes clear that online course delivery quality is very important. The other striking feature of this data about student preferences is that it is largely controlled by the instructor in the course, with the only exception being the general perceptions of online quality compared to face to face delivery.

Factors such as instructor communication and contact with other students are often taken for granted when first transitioning to teaching online from the classroom. At WPI, our own online students told us we were not doing well in these areas. We began a comprehensive annual satisfaction survey of our online students in academic year 2014-2015. Feedback from that survey heavily indicated that our online courses were falling short in terms of instructor-tostudent and student-to-student interaction. Additionally, students indicated that courses within their online program were often inconsistent, in that each instructor managed their course the way those chose, with no uniformity throughout the program.

In 2015, UPCEA published the "Hallmarks of Excellence in Online Leadership", identifying seven facets of leadership and organizational development for online education. Number three, Faculty Support, focuses on the need to provide faculty with the training, tools, support, and design resources to be successful. They highlight the key factors of onboarding, ongoing professional development and the course design-team approach as critical to success. We have a responsibility to prepare faculty for online teaching and provide them with opportunities to continue to build their skills (UPCEA, 2015).

This began our journey to develop quality standards for our university, along with a program to develop our faculty's skills for teaching online.

\section{The Need for Resources for Faculty}

When our faculty are approached to teach online, one of the common questions or concerns raised is the level of effort to convert a traditionally face-to-face class to an online format. In 2007, to proactively address quality concerns discussed in the previous section, we developed a checklist to provide as a resource for faculty so that they would have an idea what the expectations were of them as they prepared their content for online delivery. Over the years, as quality and online faculty development has evolved in higher education, our checklist has been added to and revised based on internal and external feedback from those that have utilized it. However, our checklist was never formally incorporated into our processes as an evaluative 
method for assessing quality in our online programs. We knew that needed to change, especially as reputable and high-quality evaluative scoring instruments like Quality Matters and the OLC Pillars have mainstreamed in higher education for ensuring quality in online programs.

In 2015, a robust Best Practices for Online Teaching checklist was developed for use within WPI. The checklist was the result of extensive research and benchmarking of proven models such as the Quality Matters and OLC Pillars. Along with this, a best practice syllabus template was developed as well. These were endorsed by the faculty participating in an ad-hoc online steering committee at the university. While not formally endorsed by faculty governance, these documents have been provided to all instructors teaching online since that time and those instructors have indicated that both documents are helpful resources.

The best practices tool provides faculty with guidance on online delivery and setting up their course site. It focuses on eight areas designed for faculty to check when developing or updating their online course. The areas are:

1. Course Organization and Introduction

2. Syllabus and Schedule

3. Learning Competencies and Objectives

4. Course Content

5. Communication with Students

6. Course Community (Use of Discussion Boards)

7. Assessments and Grading

8. Learner Support and Accessibility

Each section in the best practices goes through a checklist to make sure all recommended course site organization is in place. It has faculty take a look at everything from discussions boards, to student communication with peers, and ways to incorporate a well-defined course schedule and syllabus.

However, faculty still had a lot of questions about how to best take what they did well in the classroom and convert that to the online environment. Additionally, there were a lot of questions about how to best engage students and assess learning in the online environment. While the checklist and syllabus template were useful tools, they were not providing all of the necessary information for instructors.

\section{History and Overview of the Faculty Institute}

We first began researching resources and models for a formal faculty development program in the spring of 2014. After soliciting input from others involved in online faculty development through the EDUCAUSE Blend-Online listserv group, we had several phone interviews with colleagues at other Universities with strong online faculty development models. In particular, we tried to connect with colleagues whose development and delivery models were similar to ours so that we could learn from their successes. Several recommendations for a firm that offers Instructional Design services came from these interviews and knowing that this was an area in which the university was lacking, we made the connection with this firm that ultimately resulted 
in a strong partnership and the launch of our first 'Faculty Institute for Online Teaching' program, facilitated over the summer of 2015 for faculty teaching online for the university's graduate Engineering programs.

The first Faculty Institute consisted of a half-day face-to-face workshop, followed by a two-week online course, and then 10 hours of instructional design consultation hours per participant. The face-to-face workshop focused on a balance of the technology and the pedagogy while the outcomes of the online course were designed to have participants put the theory learned in the workshop into practice, while diving deeper into the pedagogy of online teaching. The main deliverable at the conclusion of the online course was a reflective action plan that would be used to kick off the formal instructional design consulting hours. Once participants concluded all three phases of the Institute, they were awarded a stipend of $\$ 1,500$ for their successful completion.

Participation in the first Faculty Institute was solicited through targeted invites to faculty teaching online sections that were well-respected within their departments and across campus. Included in the inaugural Institute were Program Directors, an Associate Department Head, the Director of our teaching center, and the Chair of the Faculty Senate. It was hoped that these influential faculty would help us socialize and grow the program while also advocating for more permanent resources to be embedded within WPI to support faculty development in online teaching.

Feedback from the first Faculty Institute was very positive and a second version was run in fall 2015 for our Business School faculty teaching for WPI's MBA program. Faculty were grateful for the opportunity to work with an instructional designer and were supportive of a request for the university to hire a full-time, permanent instructional designer. While the position was being filled, we evolved the spring 2016 Faculty Institute program slightly to separate the technology from the pedagogy during the face-to-face workshop and added in a soft requirement that faculty were required to undergo course development and build out their online courses in full prior to receiving their stipend. In support of a stronger evaluation plan, this allowed us to ensure that the recommended pedagogical best practices were formally incorporated into the course while it was being delivered. The format for the instructional design consultation hours remained the same.

An instructional designer was hired by WPI during summer 2016 and immediately began working with faculty from the spring 2016 Faculty Institute cohort that still needed to complete their consultation hours. In addition, the instructional designer evaluated the Faculty Institute program and redesigned it to better align with the most current research and to address issues brought forth by key stakeholders at the university in providing effective faculty training. This latest iteration is still broken into three similar phases: a four hour face-to-face workshop, a two week online course, and ten guaranteed hours of individual instructional design consultation. The face-to-face workshop was adjusted to focus more on helping faculty understand the needs of today's $21^{\text {st }}$ century non-traditional learners and discussion around practices and pedagogy to address these needs. The online course continued to allow participants to put theory into practice. While most of the content remained similar, additional topics such as the universal design principle and strategies for designing ADA compliant courses were added. Content delivery was redesigned to be more interactive and engaging, and assignments were developed to 
help faculty develop authentic deliverables that are transferrable into their actual online course design. With the introduction of a full-time instructional designer on staff, faculty were guaranteed ten hours of consultation time to use at their own discretion with the opportunity for more if the instructional designer's schedule allows. Completion of the Faculty Institute was further defined to state that the course must be developed and built out to the standards outlined in a provided document of the university's best practices for online teaching (Appendix A) before the stipend may be received. An action plan (Appendix B) was re-integrated into the process to help faculty and the instructional designer work toward completing the course design.

Each of the four Faculy Institutes progressed through a timeline starting in Summer 2015 and the most recent ending in Fall 2016. The first pilot round started with the instructional desgin firm and the most recent round was completed in house by our instructional designer. After each round significant improvements were made to enhance the quality of the program.

\begin{tabular}{|c|c|c|c|}
\hline Summer 2015 & Fall 2015 & Spring 2016 & Fall 2016 \\
\hline Pilot 1 & \multicolumn{1}{|c|}{ Pilot 2 } & Round 3 & Round 4 \\
$\begin{array}{l}\text { Completed with } \\
\text { consultant firm. }\end{array}$ & $\begin{array}{l}\text { Completed with } \\
\text { consultant firm for } \\
\text { The School of } \\
\text { Business. }\end{array}$ & $\begin{array}{l}\text { Completed in } \\
\text { house. }\end{array}$ & $\begin{array}{l}\text { Redesigned and } \\
\text { taught by the newly } \\
\text { hired Instructional } \\
\text { Designer. }\end{array}$ \\
\hline
\end{tabular}

\section{Results of the Faculty Institute}

After running four rounds of the Faculty Institute for Online Teaching we had 15 faculty participants for pilot one, 9 for pilot two with the School of Business, 15 for round three, and 13 faculty participants for round four. To date, we have had 52 faculty participate in at least phase one of the Faculty Institute.

\begin{tabular}{|l|l|l|l|}
\hline & $\begin{array}{l}\text { Phase 1 } \\
\text { (Face-to-face } \\
\text { workshop) }\end{array}$ & $\begin{array}{l}\text { Phase 2 } \\
\text { (Two week online } \\
\text { course) }\end{array}$ & $\begin{array}{l}\text { Phase 3 } \\
\text { (10 hours of } \\
\text { Instructional Design) }\end{array}$ \\
\hline $\begin{array}{l}\text { Completion (Number } \\
\text { of Faculty) }\end{array}$ & 52 & \multicolumn{1}{|c|}{43} & \multicolumn{1}{c|}{$43 *$} \\
\hline
\end{tabular}

*Round four to be completed by March 2017

There were 9 faculty members who did not complete the Faculty Institute with the reason being lack of time due to their schedules. The program has trained 34\% of the approximately 126 faculty teaching online. This means a minimum of 43 courses, as some faculty teach more than one course, will have been substantially modified to follow the best practices for online teaching. These best practices include organization of course sites within the learning management system, designing lectures for online delivery, feedback timelines, student to faculty engagement and 
peer to peer communication. Our goal is to have everyone teaching online to participate in this Faculty Institute within the next 1-2 years.

Faculty who have participated in the Faculty Institute are able to see immediate results in preparing and organizing their course sites after completing the program. Some of the assignments within the Faculty Institute are instantly ready for use and can be added to their course site after completion. For example, in Phase 2, each participant is asked to create a course syllabus using the recommended Syllabus Template (Appendix C) and submit it for grading on a 10-point scale. Faculty appreciate this assignment because it forces them to take another look at their syllabus and update it with the best practices recommendations. By completing their syllabus sooner rather than later, they are able to use it in their next course offering.

After surveying the faculty, a common theme brought up was the peer networking and learning from other colleagues. Some faculty are meeting for the very first time in the Faculty Institute. Each Faculty Institute has representation from several departments bringing together a diverse group with similar challenges when it comes to teaching an online course. Some quotes from participants when asked what they liked about phase one and two include: "Introduction to people who could help with my course development" and "Hearing the suggestions and strategies of other faculty members" along with "Face-to-face contacts". Having fellow colleagues meeting together for the first time boasted rich conversations about course design, identifying what's working well, and areas for improvement.

There is an end of course survey filled out by students evaluating the course and the professor once the online course is completed. After reviewing the breakdown of the quality-related question, we saw an increase in the average score after the faculty member participated in the Faculty Institute. The question looked at is "My overall rating of the quality of this course is". The response is on a 5-point scale.

\begin{tabular}{|c|l|c|}
\hline $\begin{array}{l}\text { Average Score Before } \\
\text { Participating in the Faculty } \\
\text { Institute }\end{array}$ & $\begin{array}{l}\text { Average Score After } \\
\text { Participating in the Faculty } \\
\text { Institute }\end{array}$ & Percent Increase \\
\hline 4.0 & 4.2 & $5 \%$ \\
\hline
\end{tabular}

Faculty are taking what they are learning in the Faculty Institute and applying it to their course sites by creating a learning environment more adaptable for the online student. Based on the survey results, students are rating the quality of courses higher. They are noticing the change in the course site organization, a change in content delivery methods, feedback timeliness, improved assessments, and ease of peer to peer communication.

As part of WPI's quality standards, we have incorporated a quality review process occurring every semester. There is a team designated to this process who goes into the instructor's course sites with their permission and reviews the course based of the best practices for online teaching document. Each section in the best practices has a rating and there is a final overall rating on a 4point scale. All instructors who participate in the Faculty Institute for Online Teaching are 
automatically selected to go through the quality review process. For the 2016-2017 academic year, the quality review score for the Faculty Institute participants was higher than those who did not participate in the program.

\begin{tabular}{|c|c|c|}
\hline $\begin{array}{l}\text { Average Quality Review } \\
\text { Score for Non Faculty } \\
\text { Institute Participants }\end{array}$ & $\begin{array}{l}\text { Average Quality Review } \\
\text { Score for Faculty Institute } \\
\text { Participants }\end{array}$ & Percent Increase \\
\hline 3.1 out of 4 & 3.6 out of 4 & $16 \%$ \\
\hline
\end{tabular}

Concluding that the Faculty Institute for Online Teaching is improving the overall quality of online courses taught by incorporating the best practices for online teaching along with identifying pedagogical strategies, authentic assessment activities, and a course development plan.

As the initial Faculty Institute graduates have delivered new and revised online courses deploying the concepts, we have preliminary data that is very promising. One of the techniques we are using is a course retrospective immediately following the course delivery to capture what worked well and identify opportunities for improvement.

We are finding that the reworked lecture material is much shorter and more focused on the learning outcomes. In one example, an instructor noted that the overall run-time for a particular module was reduced from 120 minutes to 70 minutes. There were twice as many shorter videos to cover half the amount of time. In reviewing the content, it was clear that nothing useful was removed because the students actually had fewer questions on the material and provided higher quality submissions for the same related assignments. Course survey results indicate that the students appreciate the revised course delivery. Faculty report finding it easier to grade higher quality results.

The deployed concepts are shifting the way online content is delivered. One Faculty Institute graduate reported, "Before the Faculty Institute, I made online course delivery a poor imitation of a traditional classroom environment - I developed the PowerPoint first, played the rambling professor second, constructed assignments with mysterious (or no) rubrics third, and then graded students to see if they accidently learned what was in the objectives last. After the Faculty Institute, I made online course delivery a learner focused environment - I developed the learning outcomes first, created assessments to match progressive proficiency second, constructed relevant assignments with mystery-free rubrics third, and then developed short and focused lectures with PowerPoint."

The flipped classroom techniques deployed in a blended online environment are proving to be successful. For this model, the lectures are recorded and posted prior to the synchronous virtual session. Instead of lecturing during the synchronous session, the time is used to implement reflective discussion content. Course survey results indicate that the students loved the polls used to solicit engagement. Preliminary statistics from one of these flipped classroom blended course offerings showed 20 times improvement in student engagement. At the end of each 2- 
hour synchronous session, the chat window averaged 600 lines in addition to the poll responses (1 class had nearly 900 entries from 18 students). In looking at the synchronous session in one class, there was a 70:1 ratio of student responses and discussion to a professor's initial question. Using the prior model, that same class had only 3-5 student responses to questions posed by the professor. As the students adjusted to the flipped classroom model, the participation rubric that measured activity (there for the whole time) and quality (meaningful participation) showed their improvement. In the first 2 weeks of the class, the average grade was $88 \%$. There were multiple weeks later in the class where the average grade was $100 \%$ (100\% of the students actively engaged for the whole 2 hours and offering at least one entry in the chat window that was judged to be meaningful).

In one online class where the material was revised as part of the Faculty Institute, there was improvement in the critical thinking demonstrated by the students. There were two factors that contribute to this. First, the Faculty Institute instruction on creating assessments aligned with objectives and reviewing possible assessment techniques changed the way the instructor developed the assessment. Instead of a discussion board assignment with some summary followed by some discussion, the assignment was split into a wiki page for the summary material and a targeted question for the discussion board intended to solicit critical thinking as response. In addition, a discussion board rubric was developed based on activity (initial post and at least 2 replies to other students) and quality (demonstrate critical thinking). A fictitious discussion board was used in the first week to demonstrate the rubric and the first assignment was for the students to grade the fictitious students using the rubric. The result was that every student in every discussion board assignment that followed for the rest of the class provided clear examples of critical thinking. The fictitious discussion board assignment provided clear examples of "good" discussion for the students and the improved discussion board design solicited critical thinking instead of summarized content from the students. Similar assignments delivered in previous versions of this class resulted in $20 \%$ of the students consistently exhibiting critical thinking vs. $100 \%$ in the revised class demonstrating critical thinking in applying course content.

\section{Lessons Learned Through the Implementation of the Faculty Institute}

As with the development of courses, the design of a training program should be approached as an iterative process. This is already evident throughout the development and implementation of the four sessions of the Faculty Institute as discussed previously. WPI plans to continue to develop and update the Faculty Institute based on feedback from each cohort, as well as to integrate the newest research in teaching and learning. In addition, the university has opportunities to expand the Faculty Institute in order to provide effective faculty development for those teaching online courses.

Understanding the $21^{\text {st }}$ century learner is a role our faculty play in creating awareness for change. Our participants voluntarily enrolled in the Faculty Institute because they are aware that the culture of education is rapidly changing and they have a genuine interest in designing and updating their online courses to reflect the current best practices. This allowed for much of the discussion within the Faculty Institute to focus on understanding $21^{\text {st }}$ century learners, ranging from how the millennial generation learns to how nontraditional students are engaging in higher education. Participants were given a safe place throughout the Faculty Institute to discuss their 
concerns about teaching these new types of learners, particularly in the online environment. In addition, the participants were asked to take on the role of a learner for part of the Faculty Institute. This helped develop their insight into the learning experience for students in the digital age. The Faculty Institute helped expand the participants' knowledge about how students learn, as well as help them shift their teaching practices to focus more heavily on helping students to develop the crucial skills that they will be expected to use in their careers and life.

One common struggle that continues to influence the effectiveness of the Faculty Institute is the timeline to allow faculty to put their new skills and knowledge into practice. While the program requires faculty to actively be developing aspects of their course, such as the course outcomes and syllabus, the bulk of the design and development phases takes place after Phase II. Faculty participating in the November 2016 offering of the program, only had four to six weeks of development time after finishing Phase II if they were scheduled to teach in the following semester. In addition, faculty who are not teaching the course for another full year after completion of the program are typically busy with other commitments and are not yet prepared to start actively working on their course. This can cause delays in their completion of the online asynchronous phase of the Faculty Institute. This can negatively impact the collaborative nature of the program, which is designed to develop a cohort of participants actively engaged in the learning process.

Another complication within faculty development stems from the variety of course styles offered by the university. Currently, some online offerings are 14 weeks while others are 10 weeks. For online courses, some are offered entirely asynchronously, while others include a two hour per week synchronous component. There are also blended courses that are asynchronous online and have two full day in-person class sessions. Each course style requires faculty to have different knowledge and skill sets for design and implementation. In addition, the Faculty Institute is not limited to professors who only teach online; thus, there are also participants who teach the majority of their courses entirely in person. This complicates how to present content so that is relevant to all participants.

The Faculty Institute is a voluntary program with an incentive in the form of a stipend. Currently, it is not a requirement from the university to teach online courses. Faculty teaching online come from various backgrounds, ranging from tenured faculty of the university to adjunct professors that have spent the bulk of their professional careers in corporate environments. Within this, there is a wide spectrum of experience with teaching online and in more traditional environments. Again, this makes it difficult for the Faculty Institute to adequately provide training that is appropriate and relevant for all participants.

Current iterations of the Faculty Institute are meant to address the complications discussed previously, as well as improvements made based on participant feedback. The goal of the Faculty Institute remains to provide faculty with a better understanding of pedagogical practices for teaching online. This can be accomplished by implementing the suggestions below.

The incentive stipend for participating in the Faculty Institute is a great tool for engaging faculty that are already involved in teaching practices at the university to go beyond the methods they have been utilizing over the years. It allows the university to provide a small compensation for 
professionals gaining a stronger understanding of pedagogy and the development of courses that are more engaging and effective beyond the teaching salary.

\section{Future Considerations}

One future consideration is to have a more rigid timeline for participation in the Faculty Institute. It would be beneficial to schedule participants to go through the Faculty Institute three to six months prior to the course offering. Given that the university currently only has one instructional designer, a six-month development window would be most ideal to maximize the quality of the course. This would require the university to try to assign course schedules to professors well in advance of the offering to ensure adequate development time. In addition, a commitment would need to be made by the professor through their action plan to actively work on the course throughout the development time. The offerings of the Faculty Institute could also be adjusted to better meet the ideal timeline window for participants by scheduling it approximately six months prior to the beginning of each term. It may also be useful to put in hard deadlines for the completion of the online phase of the Faculty Institute to ensure that there is ample time for course development.

While having a diverse cohort going through the Faculty Institute together offers strong opportunities for faculty to be exposed to various models of teaching, it also poses a challenge for making content relevant to all participants. A proposed change to the structure of the Faculty Institute would be to differentiate the experience through more personalized modules for the online portion of the workshop. The cohort would remain within the same course, but would have assignments and course materials that vary based on the style of course they will be teaching. For example, all participants would complete modules that involve the development of their syllabus and the principles of backwards design. However, they would access different modules for collaboration and engagement strategies based on the style of the course they will be teaching. This would allow the participants to explore the content in a more relevant way to meet their needs while maintaining the cohort model.

For faculty that are new to teaching online, it would be beneficial for them to undergo the Faculty Institute prior to teaching their first online or blended course. This could be implemented as part of a statement of work as a requirement for employment. The University of Central Florida requires all faculty that will be teaching online to undergo their professional development program prior to teaching a course for the university (Bauer \& Bastedo, 2016). As stated earlier, faculty support is one of the facets of leadership and organizational development for online education. By outlining the need to provide faculty with the training, tools, support, and resources necessary to be a successful online educator, we will put faculty in the best position to deliver a quality educational experience to students (UPCEA, 2015). This helps ensure that all faculty have an understanding of pedagogical practices, resources at the university, and are provided with an instructional design partner in order to create courses that meet the university's standards prior to development and implementation of their course. Mandating that new faculty complete the Faculty Institute would help the university develop a stronger, uniform development model for preparing faculty to be successful in designing and implementing online courses. 


\section{Expansion into Advanced Professional Development and Other Opportunities for Growth}

The current model for the Faculty Institute is only meant to address providing an introduction to pedagogy for teaching online. It provides a strong foundation in effective teaching for the $21^{\text {st }}$ century and allows participants to connect with resources for ongoing development through the partnership they forge with their cohort and the instructional designer. As the participants become more proficient in teaching online, their needs for professional development will change. It is important that the university look ahead to developing more advanced workshops for experienced online faculty. Advanced versions of the Faculty Institute could mirror the same design or could be broken into smaller workshops based on specific topics.

As the Faculty Institute continues to be implemented, the number of faculty being supported by the instructional designer will continue to grow. It is likely that the university will need to expand this role in order to best support the participants. The partnership forged with the instructional designer is a major component of the Faculty Institute and plays a crucial role in effective course development for the university, so it is imperative that an instructional designer continues to be assigned to each faculty participant as the program expands.

The Faculty Institute for Online Teaching plays in integral role in faculty professional development. The program allows both new and seasoned faculty to take a fresh look at teaching an online course. Learning how to organize their course site based on best practices for online delivery, student to faculty engagement and peer to peer communication are key for teaching a successful on online course. It is hoped that this program will continue to thrive and that the best practices will be adopted by the full faculty. 


\section{Reference Materials}

Allen, I. Elaine \& Seamen, Jeff, 2014, Grade Change: Tracking Online Education in the United States. Online study sponsored by the Babson Survey Group.

Clinefelter, Dr. David L. \& Aslanian, Carol, 2015, Online College Students 2015:

Comprehensive Data on Demands and Preferences. A joint project of The Learning House, Inc. and Aslanian Market Research

UPCEA Hallmarks of Excellence in Online Leadership. The UPCEA Hallmarks of Excellence in Online Leadership was developed by the UPCEA National Task Force on Hallmarks of Excellence in Online Leadership: Jay A. Halfond, Boston University \& Senior Fellow UPCEA Center for Online Leadership and Strategy (chair); Andrew Casiello, Old Dominion Universiy; Dave Cillay, Washington State University; Nancy Coleman, PlattForm; Vickie Cook, University of Illinois Springfield; John LaBrie, Northeastern University; Mary Niemiec, University of Nebraska; and Witt Salley, Clemson University.

Bauer, S., \& Bastedo, K., November 17, 2016, Advanced Professional Development for Experienced Online Faculty. Lecture presented at Online Learning Consortium: Accelerate 2016, Orlando. 
Appendices 


\section{Appendix A (Best Practices Document)}

\section{Best Practices for Online Course Development Checklist - Online Delivery Quality Rubric}

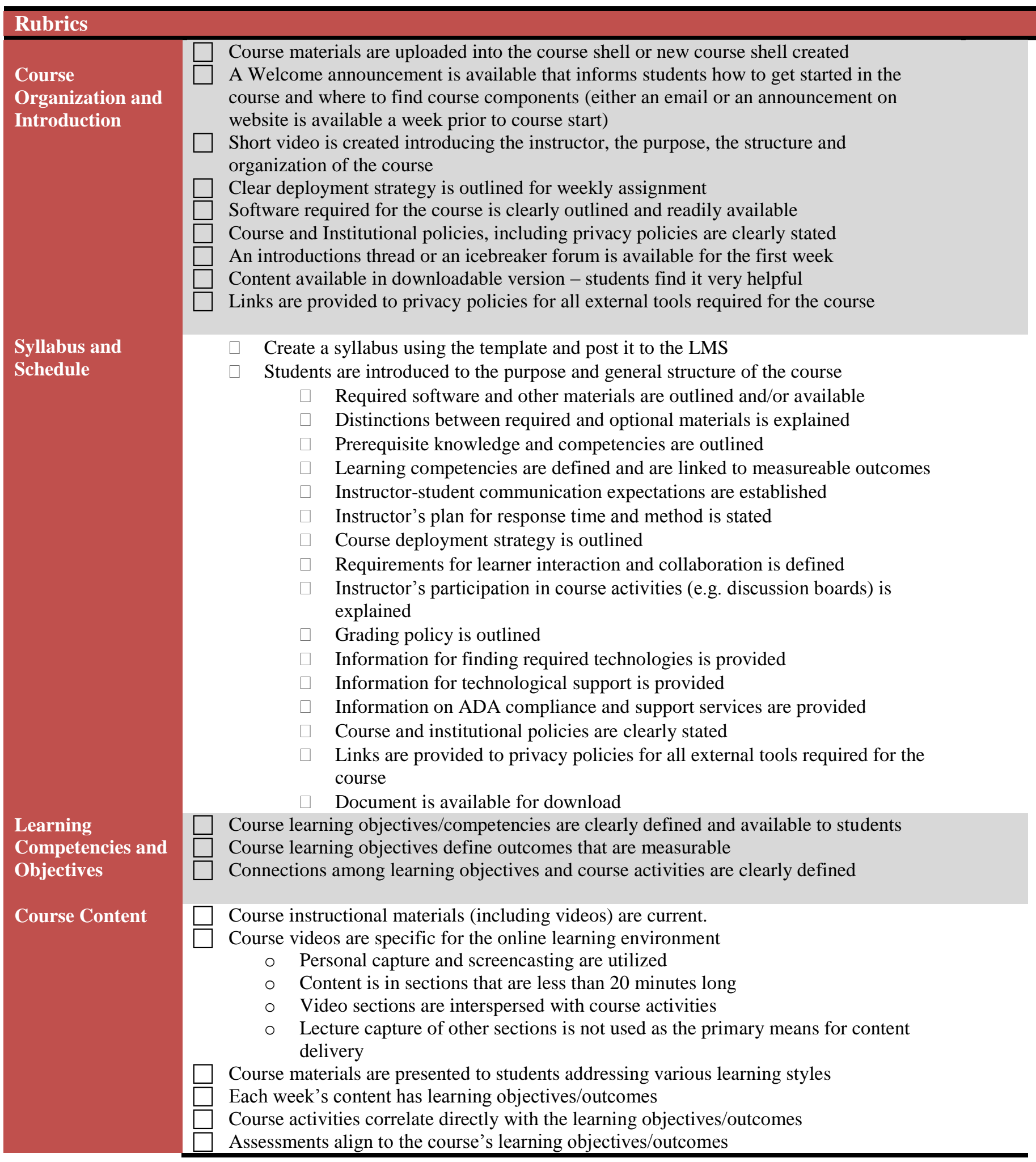




\begin{tabular}{|c|c|}
\hline & $\begin{array}{l}\text { Formative assessments and/or benchmark activities are integrated to track student progress } \\
\text { toward proficiency of the course objectives/outcomes } \\
\text { A variety of course activities are available for students to work actively with content } \\
\text { Course content is published on a consistent weekly basis following the format outlining in } \\
\text { the course syllabus } \\
\text { Materials are available for download }\end{array}$ \\
\hline
\end{tabular}

\begin{tabular}{|c|c|}
\hline $\begin{array}{l}\text { Course } \\
\text { Community } \\
\begin{aligned} \text { Activities } \\
\text { - } \\
\text { Forums } \\
\text { Discussio } \\
\text { n Board } \\
\text { Alternative virtual } \\
\text { Classroom space }\end{aligned}\end{array}$ & $\begin{array}{l}\text { Build a course community through student to student interaction such as use of } \\
\text { teams/group projects, discussion boards, etc. } \\
\text { Learning activities support learning competencies } \\
\text { The requirements for learner interaction are clearly outlined } \\
\text { Course provides opportunities for student to student interaction } \\
\text { The grading policy of forums and student to student interaction is clearly outlined (required } \\
\text { participation in discussion board that is graded is recommended } \\
\text { Weekly "burning Issues" discussion thread is created and explained } \\
\text { All forum topics have been created (consider } 2-3 \text { topics per week) } \\
\text { Instructor's participation in Discussion Board activity is explained and closely followed } \\
\text { (posting 2-3 times per week)(*) }\end{array}$ \\
\hline $\begin{array}{l}\text { Assessments and } \\
\text { Grading }\end{array}$ & $\begin{array}{l}\text { The assessments clearly align to the stated learning objectives } \\
\text { The course grading policy is outlined clearly through the course } \\
\text { There are benchmarks through the course allowing students to track their learning progress }\end{array}$ \\
\hline
\end{tabular}

*aligned with results of Bailie's investigation

References

Bailie, Jeffrey L. (2015). Online Graduate Instruction: What Faculty Consider Reasonable In Relation to What Students Expect. http://jolt.merlot.org/vol11no1/Bailie_0315.pdf 
Sandra M. Harris, Yvonne I. Larrie, Marianne Castano-Bishop. Development of the Student Expectations of Online Learning Survey (SEOLS): A Pilot Study http://www.westga.edu/ distance/ojdla/winter144/harris_larrier_bishop144.html

Quality Matters Rubric, https://www.qualitymatters.org/rubric

The QLOT Rubric - Quality Online Learning and Teaching (2014), California State University, http://www.csuchico.edu/eoi/ 
Appendix B (Action Plan)

\section{ACTION PLAN}

Using the accompanying action plan guide to fill out the template below. You should have at least one goal for each section and the bulk of your action plan will most likely be within the Design and Development areas. Feel free to add and/or delete rows as needed.

Planning

\begin{tabular}{|c|c|c|c|c|}
\hline GOAL: & & & & \\
\hline Step or Task & $\begin{array}{c}\text { Resources to } \\
\text { Use }\end{array}$ & Support Needed & $\begin{array}{l}\text { Performance } \\
\text { Measure }\end{array}$ & Target Date \\
\hline & & & & \\
\hline & & & & \\
\hline GUAL: & & & & \\
\hline Step or Task & $\begin{array}{c}\text { Resources to } \\
\text { Use }\end{array}$ & Support Needed & $\begin{array}{l}\text { Performance } \\
\text { Measure }\end{array}$ & Target Date \\
\hline & & & & \\
\hline & & & & \\
\hline GOAL: & & & & \\
\hline Step or Task & $\begin{array}{c}\text { Resources to } \\
\text { Use }\end{array}$ & Support Needed & $\begin{array}{l}\text { Performance } \\
\text { Measure }\end{array}$ & Target Date \\
\hline & & & & \\
\hline & & & & \\
\hline
\end{tabular}

Design

\begin{tabular}{|c|c|c|c|c|}
\hline \multicolumn{5}{|l|}{ GOAL: } \\
\hline Step or Task & $\begin{array}{c}\text { Resources to } \\
\text { Use }\end{array}$ & Support Needed & $\begin{array}{l}\text { Performance } \\
\text { Measure }\end{array}$ & Target Date \\
\hline & & & & \\
\hline \multirow{2}{*}{\multicolumn{5}{|c|}{ GOAL: }} \\
\hline & & & & \\
\hline Step or Task & $\begin{array}{c}\text { Resources to } \\
\text { Use }\end{array}$ & Support Needed & $\begin{array}{l}\text { Performance } \\
\text { Measure }\end{array}$ & Target Date \\
\hline & & & & \\
\hline
\end{tabular}




\begin{tabular}{|l|c|l|l|l|}
\hline \multicolumn{2}{|c|}{} & & \\
\hline GOAL: & $\begin{array}{c}\text { Resources to } \\
\text { Use }\end{array}$ & Support Needed & $\begin{array}{c}\text { Performance } \\
\text { Measure }\end{array}$ & Target Date \\
\hline & & & & \\
\hline & & & & \\
\hline
\end{tabular}

Development

\begin{tabular}{|c|c|c|c|c|}
\hline \multicolumn{5}{|l|}{ GOAL: } \\
\hline Step or Task & $\begin{array}{c}\text { Resources to } \\
\text { Use }\end{array}$ & Support Needed & $\begin{array}{l}\text { Performance } \\
\text { Measure }\end{array}$ & Target Date \\
\hline & & & & \\
\hline \multirow{2}{*}{\multicolumn{5}{|c|}{ GOAL: }} \\
\hline & & & & \\
\hline Step or Task & $\begin{array}{c}\text { Resources to } \\
\text { Use }\end{array}$ & Support Needed & $\begin{array}{l}\text { Performance } \\
\text { Measure }\end{array}$ & Target Date \\
\hline & & & & \\
\hline \multicolumn{5}{|l|}{ GOAL: } \\
\hline Step or Task & $\begin{array}{c}\text { Resources to } \\
\text { Use }\end{array}$ & Support Needed & $\begin{array}{l}\text { Performance } \\
\text { Measure }\end{array}$ & Target Date \\
\hline & & & & \\
\hline & & & & \\
\hline
\end{tabular}




\section{Appendix C (Syllabus Template for Online Courses)}

\section{Name of Course \\ Department \\ Term}

\section{Instructor:}

Name

Contact Information (email, phone, office location, etc.)

\section{Textbook (and/or other Required Materials):}

Be sure to include title, author(s), and ISBN number

Indicate whether it is a required text or a supplemental resource

\section{Course Description:}

A brief paragraph that mildly extends from the catalog description. Focus on overlying concepts, not minutia.

\section{Prerequisite Courses:}

If your course has required or recommended prerequisite courses, list them here.

\section{Learning Outcomes:}

By the completion of this course, learners will be able to:

-Focus on skills that are transferrable to post-course life, work environments, or further education

-Use action verbs such as: explain, develop, evaluate, apply, solve

-Evaluate your course and limit it to 5 major outcomes

\section{Communication:}

Provide information on how students should contact you and the approximate wait time for a response. Be specific - provide times for office hours, etc.

\section{Course Approach:}

Provide students with:

- Start and end days for each week (e.g. weeks begin on Monday at 7am and close on Sunday at 11:59pm)

- State how many weeks the course will run

- Explain basic format of your setup for the LMS - modules, pages, calendar use, etc.

- Provide a quick blurb about what students should expect for content delivery (lecture capture, personal capture, demonstration videos, simulations, reading, etc.)

- Provide a short explanation of student expectations that recur on a weekly basis (e.g. all student work will be turned in by Sunday 11:59pm of the given week) 


\section{Schedule of Weekly Classes:}

Provide a detailed course outline that breaks down into individual weeks. This should include: the main topic, all reading and content that students should review, and all assignments, assessments, and activities that are due. It is most helpful to provide this information in an easyto-read table that students can refer to throughout the course. Within the Canvas LMS, you can also hyperlink to specific materials directly from your course outline.

\begin{tabular}{|c|l|l|}
\hline Week/Topic & Reading/Content Materials & Assignments/Activities \\
\hline 1: Intro to UBD & & \\
\hline 2 & & \\
\hline 3 & & \\
\hline 4 & & \\
\hline
\end{tabular}

\section{Course Requirements:}

\section{Grade Determination Breakdown}

If you have a variety of categories, outline them here. Provide information about weighting of categories.

2. Assignments

Explain the various types of assignments and the general expectations. Inform students of where to find more detailed instructions for specific assignments. If certain types of assignments are recurring, provide hard due dates (e.g. discussions are always due at 11:59pm on Wednesday).

3. Assessment and Feedback Plan

Provide an outline of the various course assignments, their percent, who will provide feedback, and when students can expect to receive feedback. This should give students a quick view of all the assignments and the progression toward a summative assessment.

\section{Late Work Policy}

Provide a short blurb highlighting your late work policy, if applicable. If you will not be accepting late work, state that explicitly

5. Class Participation Expectations and Criteria

If participation, whether live or online in a discussion board or group work, provide an in-depth description of your expectations. Insert your grading rubric for discussion posts and peer feedback here, if applicable.

\section{Technical Requirements:}

If students need to access particular software, state it here. Also provide them information for where to turn if they experience technical difficulties, particularly regarding issues with the LMS.

\section{Library Access:}

Provide the statement below or a similar variation.

As a student, you have access to a variety of resources through the library. Use the link here to access databases, e-journals, and/or e-books. You will be required to log in with your username and password to access materials. 


\section{POLICIES}

\section{Academic Integrity:}

Provide the statement below or a similar variation.

You are expected to be familiar with the Student Guide to Academic Integrity that is downloadable from here. Consequences for violating the Academic Honest Policy range from earning a zero on the assignment, failing the course, or being suspended or expelled. Common examples of violations include:

- Copying and pasting text directly from a source without providing appropriately cited credit

- Paraphrasing, summarizing, or rephrasing from a source without providing appropriate citations

- Collaborating on individual assignments

- Turning in work where a good portion of the work is someone else's, even if properly cited

\section{Academic Accommodations:}

Courses should be compliant with the American Disability Act. Provide the following statement or a similar variation. If you, as the instructor, have questions about making content accessible to all learners, reach out to the Office of Disability Services.

We strive to create an inclusive environment where all students are valued members of the class community. If you need course adaptations or accommodations because of a disability, or if you have medical information to share with us that may impact your performance or participation in this course, please make an appointment with us as soon as possible. If you have approved accommodations, please request your accommodation letters online through the Office of Disability Services student portal. If you have not already done so, students with disabilities who need to utilize accommodations for this course are encouraged to contact the Office of Disability Services as soon as possible to ensure that such accommodations are implemented in a timely fashion.

Email - DisabilityServices@xx.edu Phone - (xxx) xxx-xxxx

\section{Grading Policy:}

Provide up-to-date grading policy (use statement below or a similar variation). Final course grades are based on a student's performance as follows:

\begin{tabular}{|c|c|}
\hline $\begin{array}{c}\text { Letter } \\
\text { Grade }\end{array}$ & Percentage \\
\hline A & $90-100$ \\
\hline B & $80-89$ \\
\hline C & $70-79$ \\
\hline D & $60-69$ \\
\hline F & $<60$ \\
\hline
\end{tabular}

Course incompletes may be granted if the major part of the course is completed; however, no additional credit can be given for missed class discussions or teamwork beyond the end of the course. In addition, in the case of an incomplete, the student is responsible for handing in the final work within the required timeframe of one (1) year. After this time, an incomplete grade changes to a failing $(\mathrm{F})$ grade. 